\title{
EFFECTIVENESS OF CINNAMON TEA IN REDUCING WEIGHT AMONG LATE OBESE ADOLESCENCE
}

\author{
MANGALA GOWRI P, MARY MINOLIN T, THENMOZHI P*, MEENA P, VIMALA S
}

Department of Nursing, Saveetha College of Nursing, Saveetha University, Chennai, Tamil Nadu, India. Email: thenmozhi.sethu@gmail.com Received: 30 November 2016, Revised and Accepted: 16 January 2017

\section{ABSTRACT}

Objective: The objective of the study is to determine the effectiveness of cinnamon tea in reducing weight among late obese adolescent.

Methods: Pre-experimental research design was adopted to conduct the study with 30 samples who met the inclusion criteria. Cinnamon tea was given for the samples for 15 days, and their weight and body mass index (BMI) was measured before as well as after the intervention. Data were analyzed using descriptive and inferential statistics.

Results: Out of 30 samples in pretest, $70 \%$ of them had overweight and $30 \%$ of them had Class I obesity with the body mass index mean value of 28.75 and 2.72 standard deviation. In post-test, $20 \%$ of them were normal weight, $66.67 \%$ of them were overweight, and $13.33 \%$ of them were Class I obesity. The post-test body mass index mean was 27.45 with 3.34 standard deviation. Paired t-test revealed that cinnamon tea was found to be effective in reducing weight at the level of ${ }^{*} \mathrm{p}<0.05$.

Conclusion: The findings of this study revealed that the prescribed cinnamon tea resulted in an improvement reduction of weight. However, we need further studies with larger samples to investigate the effect of cinnamon in reducing the different factors like weight, BMI, hip waist circumference level in obese adolescents.

Keywords: Obesity, Childhood obesity, Adolescent, Cinnamon, Body mass index, Weight, Cinnamon tea.

(C) 2017 The Authors. Published by Innovare Academic Sciences Pvt Ltd. This is an open access article under the CC BY license (http://creativecommons. org/licenses/by/4. 0/) DOI: http://dx.doi.org/10.22159/ajpcr.2017.v10i4.16420

\section{INTRODUCTION}

The term overweight refers to excess body weight for a particular height, whereas the term obesity is used to define excess body fat. Obesity has been named among the highly occurring noncommunicable disease affecting around 39\% of world's population. Worldwide, obesity trends are causing serious public health concern and in many countries threatening the viability of basic health-care delivery. Indian data regarding current trends in childhood obesity are emerging. A recent study conducted among 24,000 school children in South India showed that the proportion of overweight children increased from $4.94 \%$ of the total students to $6.57 \%$ [1].

Childhood obesity is a global phenomenon affecting all socioeconomic groups, irrespective of age, sex, or ethnicity. Etiopathogenesis of childhood obesity is multifactorial and includes genetic, neuroendocrine, metabolic, psychological, environmental, and sociocultural factors. Many comorbid conditions such as metabolic, cardiovascular, psychological, orthopedic, neurological, hepatic, pulmonary, and renal disorders are seen in association with childhood obesity.

An individual's eating and physical activity behaviors are heavily influenced by social contexts where they are brought up. Adolescent age group is more vulnerable to consume fast food which contains large portions of high fat and low fiber food [2]. The sedentary activities such as television viewing, playing games in the mobile, computer laptop and tablet are the major causes for childhood obesity [3]. Consuming a high-calorie diet without adequate exercise to burn off excess fat is the leading cause of obesity. As we are aware, more the glucose levels imply more the insulin gets secreted into the blood, and more the insulin implies more of fat storage which leads to weight gain in the long run.

Children and adolescents of poor socioeconomic status tend to consume less quantities of fruits and vegetables and to have a higher intake of total and saturated fat [4-6]. Early rebound of body mass index (BMI) is linked to glucose intolerance and diabetes in adults [7]. The risk of obesity persisting into adulthood is higher among obese adolescents than among younger children [8]. Observations suggest that up to $80 \%$ of overweight adolescents will become obese adults [9].

Obesity is an independent risk factor for cardiovascular diseases and significantly increases the risk of morbidity and mortality. The last two decades have witnessed an increase in health-care costs due to obesity and related issues among children and adolescents. The treatment of overweight and obesity in children and adolescents requires a multidisciplinary, multi-phase approach, which includes dietary management, physical activity enhancement, restriction of sedentary behavior, pharmacotherapy, and bariatric surgery.

Weight loss is the best way to combat obesity. There are many nutritional supplements, herbs, and spices that can provide benefits for weight loss. Cinnamon is one such spice that is used for weight loss especially combined with honey. Several available experimental evidence suggests that cinnamon can play role in balancing body insulin levels, cholesterol levels, glucose levels aiding in weight loss. Thus, cinnamon can be opted as among wise options for weight loss and management. Cinnamon is common as well as among the oldest known spice, condiment and flavoring agent in the world [1].

A research group from Germany published a study in 2014 demonstrating role of cinnamon in mediating changes in metabolic pathways leading to decrease in liver fat and balancing blood glucose levels. A Canadian Research Group published their study in Molecular Nutrition and Food Research, 2006. The study concluded that the rate of glucose uptake by 3T3 adipocytes (adipose cells) increased on treated with cinnamon extract. Another study published in Diabetic Journal published the research which elucidated possible role of cinnamtannin B1 as the active molecule responsible for elevating glucose uptake by 
glucose transporter Type 4, increase in glucose metabolism, inhibiting gluconeogenesis, decreasing low-density lipoprotein (LDL) levels, and increasing high-density lipoprotein levels which mean that weight can be managed by managing one's blood pressure (BP) and blood glucose levels [10]. Balijepalli et al. had reviewed the pharmacological actions of Cinnamomum species and literature on scientifically proven biological uses of Cinnamomum using the databases; PubMed, Scopus, Science Finder and Google Scholar. Scientific studies have shown that the Cinnamomum species possess anesthetic, anodyne, antibacterial, antidiabetic, antifungal, anti-inflammatory, antiplatelet, antioxidant, antipyretic, antiseptic, antispasmodic, antiulcer, antiviral, chemopreventive, choleretic, cytotoxic, hypolipidemic, immunostimulant, lipolytic, and sedative activities [11]. Cinnamon is a highly delicious spice used in sweet and savoury foods. It has the lots of nutritional facts and medicinal value. Among many potential effects of cinnamon the researchers interested to conduct a study to determine the effectiveness of cinnamon on reducing the weight of the obese late adolescent.

\section{METHODS}

The research approach used in the study was quantitative approach using pre-experimental one group pre- and post-test research design. The study was conducted with 30 samples in Saveetha College of Nursing after obtaining approval from ethical clearance with reference number 014/05/2016/IEC/SU and formal permission from the authority. The samples who met the inclusion criteria were selected by convenient sampling technique. Adolescents with Class II obesity, obesity due to the side effects of medication or disease condition, peptic ulcer, oral mucosal ulceration, and obesity-related diseases were excluded. Explained the study in detail and obtained informed consent from the samples. Demographic variables were collected by self-administered questionnaire and followed by weight and height was checked by standardized and calibrated digital scale and stadiometer. BMI was calculated and classified obesity according to the World health Organization guidelines. Samples were received the $50 \mathrm{ml}$ of cinnamon tea which contains $5 \mathrm{~g}$ of cinnamon powder for 15 days in the morning in empty stomach. At the end of $15^{\text {th }}$ day, level of obesity was assessed. Confidentiality was maintained throughout the procedure. Collected data were analyzed using both descriptive and inferential statistics.

\section{RESULTS}

\section{Distribution of demographic variables}

In this 30 late obese adolescents were recruited during the study period, of these, the majority of the sample were female and fall in the age group between 17 and 18 years. $100 \%$ of them were non-vegetarian and $63.33 \%$ of them were consuming more frequently. Around $76 \%$ of them had no family history of obesity and history of childhood obesity. The majority of them had no stress and no habits of doing yoga and exercise as shown in Table 1.

\section{Level of obesity before and after the intervention}

Among 30 samples, in pretest $70 \%$ of them had overweight and $30 \%$ of them had Class I obesity. In post-test, $20 \%$ of them were normal weight, $66.67 \%$ of them were overweight, and $13.33 \%$ of them were in Class I obesity as shown in Fig. 1

Mean and standard deviation of BMI and weight in late obese adolescents

The pretest mean of BMI was 28.75 with 2.72 standard deviation, and post mean was 27.45 with 3.34 standard deviation. The pretest mean of weight was 72.05 with 8.98 standard deviation, and post mean was 69.2 with 7.41 standard deviation as shown in Table 2.

Effectiveness of cinnamon extract in reducing weight among late obese adolescent

The calculated " $t$ " value for weight in the study group was $t=5.96$ which is found to be statistically significant at the level of ${ }^{*} p<0.05$ level as shown in Table 3.
Table 1: Distribution of demographic variables of the participants

\begin{tabular}{|c|c|c|}
\hline S. No. & Demographic variables & Frequency (\%) \\
\hline \multirow[t]{4}{*}{1} & Age in years & \\
\hline & $17-18$ & $19(63.33)$ \\
\hline & $19-20$ & $10(33.34)$ \\
\hline & 21 & $1(3.33)$ \\
\hline \multirow[t]{3}{*}{2} & Sex & \\
\hline & Male & 7 (23.33) \\
\hline & Female & $23(76.67)$ \\
\hline \multirow[t]{3}{*}{3} & Dietary habits & \\
\hline & Vegetarian & $0(-)$ \\
\hline & Non-vegetarian & $30(100)$ \\
\hline \multirow[t]{3}{*}{4} & Frequency of eating & \\
\hline & Less frequent & $11(36.67)$ \\
\hline & More frequent & $19(63.33)$ \\
\hline \multirow[t]{4}{*}{5} & Habits of consuming junk food & \\
\hline & Never & $8(26.67)$ \\
\hline & Occasional & $8(26.67)$ \\
\hline & Often & $14(46.66)$ \\
\hline \multirow[t]{3}{*}{6} & Family history of obesity & \\
\hline & Yes & $8(26.67)$ \\
\hline & No & $22(73.33)$ \\
\hline \multirow[t]{3}{*}{7} & History of childhood obesity & \\
\hline & Yes & 7 (23.33) \\
\hline & No & $23(76.67)$ \\
\hline \multirow[t]{3}{*}{8} & Sleeping pattern & \\
\hline & Regular & $14(46.67)$ \\
\hline & Irregular & $16(53.33)$ \\
\hline \multirow[t]{3}{*}{9} & Stress & \\
\hline & Yes & $2(6.67)$ \\
\hline & No & $28(93.33)$ \\
\hline \multirow[t]{3}{*}{10} & Habits of doing exercise/yoga & \\
\hline & Yes & $7(73.33)$ \\
\hline & No & $23(23.33)$ \\
\hline
\end{tabular}

Table 2: Distribution of pre- and post-test mean and standard deviation of BMI and weight in late obese adolescents

\begin{tabular}{lll}
\hline Physical & Mean \pm SD & \\
\cline { 2 - 3 } Parameters & Pre-test & Post-test \\
\hline BMI & $28.75 \pm 2.72$ & $27.45 \pm 3.34$ \\
Weight & $72.05 \pm 8.98$ & $69.2 \pm 7.41$ \\
\hline
\end{tabular}

BMI: Body mass index, SD: Standard deviation

Table 3: Determine the effectiveness of cinnamon extract in reducing weight among late obese adolescent

\begin{tabular}{lll}
\hline Level of Weight & Mean \pm SD & Paired t-test \\
\hline Pre-test level of weight & $72.05 \pm 8.98$ & t value: 5.96 \\
Post-test level of & $69.2 \pm 7.41$ & df: 29 \\
weight & & p<0.05 \\
& & Significant \\
\hline
\end{tabular}

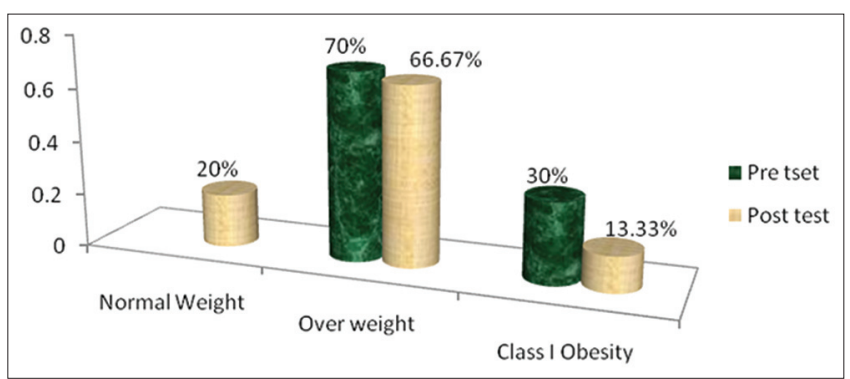

Fig. 1: The level of obesity before and after the intervention among the participants $(n=30)$ 
Association between the pretest level of obesity and demographic variables

Chi-square test reveals that there is a significant association between dietary habits, Habits of doing exercise/yoga at the level of ${ }^{*} \mathrm{p}<0.05$ with the level of obesity.

\section{DISCUSSION}

The last two decades of the previous century have witnessed dramatic increase in health-care costs due to obesity and related issues among children and adolescents [12]. Diet and exercise are fundamental elements for losing weight. In this study, the Chi-square test also founded that there is an association between the dietary habits and the level of obesity. Although many complementary therapies are promoted for the treatment of obesity, few are truly therapeutic. The present investigation examined the effect of cinnamon tea intervention on the reduction of obesity among 30 late obese adolescence. Numbers of studies related to the effects of cinnamon in reduction of weight among human being are very limited. There are few research studies have been undertaken in rats as animal study which proven that consumption of cinnamon extract on BP and blood glucose level which shows that drastic reduction in BP and insulin secretion as well utilization. Khan et al. studied the effects of 1,3 , and $6 \mathrm{~g}$ /day of whole cinnamon powder on fasting blood glucose and serum lipids in 60 people with poorly controlled Type 2 diabetes from Pakistan and after 40 days of supplementation fasting blood glucose decreased by $18-29 \%$, cholesterol decreased by $12-26 \%$, LDL cholesterol decreased by 7-27\%, and triacylglycerol decreased by $23-30 \%$ [13]. More recently, Mang et al. supplemented 79 people with Type 2 diabetes from Germany with $3 \mathrm{~g}$ /day cinnamon powder or a placebo for 4 months, and the findings of the study concluded that moderate effect in reducing fasting plasma glucose concentration in diabetic patients with poor glycemic control [14].

This study findings reveal that consuming cinnamon tea with $5 \mathrm{~g} /$ day with honey for 2 weeks leads to significant reduction in weight at the level of $\mathrm{p}<0.05$ which was in concordance with a study conducted by Vafa et al. They had conducted a clinical trial recently with 44 samples by administration of $3 \mathrm{~g}$ of cinnamon per day for 8 weeks and reported that cinnamon may have a moderate effect in improving glycemic status indicators and fasting blood glucose, hemoglobin A1c (HbA1c), triglyceride, weight, BMI, and body fat mass decreased significantly compared to baseline [15]. Qin et al. had conducted the study to assess the effect of the 30 and $300 \mathrm{mg} / \mathrm{kg}$ body weight for 3 weeks cinnamon extract on the insulin action in awaked rats by the euglycemic clamp and further analyzed possible changes in insulin signaling occurred in skeletal muscle, and the results suggest that the cinnamon extract would improve insulin action via increasing glucose uptake in vivo, at least in part through enhancing the insulin-signaling pathway in skeletal muscle [16].

Other studies are also indirectly supporting these study findings. Kumar and Prakash had conducted a comparative analysis of antioxidant activity and phytochemical screening of some Indian medicinal plants with composition of Cassia fistula, Acacia catechu, Cinnamomum cassia and Citrus limon in bark extracts and showed the antioxidant properties of medicinal plants playing part significantly in anti-inflammatory, heart failure, and carbohydrate metabolism disorders [17]. Akilen et al. had conducted a study was to review and evaluate the effect of shortterm administration of cinnamon on BP regulation and it shows that significant reduction in systolic BP (SBP) by $5.39 \mathrm{mmHg}$ and diastolic BP by $2.6 \mathrm{mmHg}$ at $95 \%$ confidence interval. Although cinnamon shows hopeful effects on BP-lowering potential, it would be premature to recommend cinnamon for $\mathrm{BP}$ control because of the limited number of studies available [18]. Mustaffaa et al. had designed this study to evaluate the antidiabetic and antihyperlipidemic effect of Cinnamomum iners leaves, and the findings concluded that $C$. iners leaves showed antidiabetic properties and hypolipidemic effects. The increased antidiabetic potential of CF over ME and SF-1 over CF is presumably due to its partial purification achieved by fractionation which resulted in increase in quantity of cinnamic aldehyde [19]. Wainstein et al. had conducted a study with 59 subjects with Type 2 diabetes mellitus by administration of $1200 \mathrm{mg}$ of cinnamon per day and results revealed that SBP declined from baseline values by $3.4 \pm 11.4 \mathrm{mmHg}$. Although cinnamon added to the diets of spontaneously hypertensive rats has been shown to decrease SBP [20]. Kalsi et al., 2015, had conducted a study on current treatments for Type 2 diabetes, their side effects and possible complementary treatments and the findings of the study suggested that there is an urgent need to come up with complementary treatments such as physical exercise, dietary supplements, and nutraceuticals that can be used as therapy along with the drugs to reduce the dependence on the drugs and better manage the disease. Nutraceuticals include cinnamon and garlic among the cinnamon promotes insulin secretion and glucose uptake [21].

These study findings are accordance with this study directly and indirectly because of the study shows that significant reduction in blood sugar and BP which in turn decrease the weight and BMI. However, this study mainly and only focused on the obese adolescence, and the findings may not be applied to the adults obese because they are influenced by many extraneous variables such as habits such as smoking, alcoholism, physical inactivity, and comorbid problems like diabetes mellitus and hypertension. The result of the study is limited in biochemical markers related to obesity such as lipid profile, fasting blood sugar, and HbA1c. Hence, the investigators planned to conduct further study with adult obese with Type 2 diabetes mellitus and hypertension by measuring related biochemical markers.

\section{CONCLUSION}

Consuming cinnamon tea is cost-effective do not cost extra time and it is effective in decreasing the body weight which will help to reduce the obesity and prevent the obesity-related complications. The amount and frequency of cinnamon that reduces the weight among obesity adolescent not sufficiently examined in research studies. Hence, it is difficult to determine the amount, frequency and duration of consumption of cinnamon which provides the best benefit to obese adolescents. In this study, we proposed that $5 \mathrm{~g}$ of cinnamon containing tea with honey for 2 weeks. In conclusion, the findings of this study revealed that the prescribed cinnamon tea resulted in an improvement reduction of weight. However, we need further studies with larger samples to investigate the effect of cinnamon in reducing the different factors like weight, BMI, hip waist circumference level in obese adolescents.

\section{ACKNOWLEDGMENT}

Researchers thank all the participants for their valuable contribution.

\section{REFERENCES}

1. Raj M, Sundaram KR, Paul M, Deepa AS, Kumar RK. Obesity in Indian children: Time trends and relationship with hypertension. Natl Med J India 2007;20(6):288-93.

2. Ebbeling CB, Feldman HA, Osganian SK, Chomitz VR, Ellenbogen SJ, Ludwig DS. Effects of decreasing sugar-sweetened beverage consumption on body weight in adolescents: A randomized, controlled pilot study. Pediatrics 2006;117(3):673-80.

3. Gortmaker SL, Must A, Sobol AM, Peterson K, Colditz GA, Dietz WH. Television viewing as a cause of increasing obesity among children in the United States, 1986-1990. Arch Pediatr Adolesc Med 1996;150(4):356-62.

4. Neumark-Sztainer D, Story M, Resnick MD, Blum RW. Correlates of inadequate fruit and vegetable consumption among adolescents. Prev Med 1996;25(5):497-505.

5. Krebs-Smith SM, Cook A, Subar AF, Cleveland L, Friday J, Kahle LL. Fruit and vegetable intakes of children and adolescents in the United States. Arch Pediatr Adolesc Med 1996;150(1):81-6.

6. Kennedy E, Powell R. Changing eating patterns of American children: A view from 1996. J Am Coll Nutr 1997;16(6):524-9.

7. Bhargava SK, Sachdev HS, Fall CH, Osmond C, Lakshmy R, Barker DJ, et al. Relation of serial changes in childhood body-mass 
index to impaired glucose tolerance in young adulthood. N Engl J Med 2004;350(9):865-75

8. Whitaker RC, Wright JA, Pepe MS, Seidel KD, Dietz WH. Predicting obesity in young adulthood from childhood and parental obesity. N Engl J Med 1997;337(13):869-73.

9. Daniels SR, Arnett DK, Eckel RH, Gidding SS, Hayman LL, Kumanyika S, et al. Overweight in children and adolescents: Pathophysiology, consequences, prevention, and treatment. Circulation 2005;111(15):1999-2012.

10. Available from: http:/www.benefitsfromcinnamon.com/benefits/ cinnamon-for-weight-loss.

11. Balijepalli MK, Buru AS, Sakirolla R, Pichika MR. Cinnamomum genus: A review on its biological activities. Int J Pharm Pharm Sci 2017;9(2).

12. Wang G, Dietz WH. Economic burden of obesity in youths aged 6 to 17 years: 1979-1999. Pediatrics 2002;109(6):E81-1.

13. Khan A, Safdar M, Ali Khan MM, Khattak KN, Anderson RA. Cinnamon improves glucose and lipids of people with Type 2 diabetes. Diabetes Care 2003;26(12):3215-8.

14. Mang B, Wolters M, Schmitt B, Kelb K, Lichtinghagen R, Stichtenoth DO, et al. Effects of a cinnamon extract on plasma glucose, $\mathrm{HbA}$, and serum lipids in diabetes mellitus Type 2. Eur J Clin Invest 2006;36(5):340-4.
15. Nasri H, Madihi Y, Marikhi A. Commentary on: Effects of cinnamon consumption on glycemic status, lipid profile and body composition in Type 2 diabetic patients. Int J Prev Med 2013;4(5):618-9.

16. Qin B, Nagasaki M, Ren M, Bajotto G, Oshida Y, Sato Y. Cinnamon extract (traditional herb) potentiates in vivo insulin-regulated glucose utilization via enhancing insulin signaling in rats. Diabetes Res Clin Pract 2003;62(3):139-48.

17. Kumar U, Prakash V. Comparative analysis of antioxidant activity and phytochemical screening of some Indian medicinal plants. Int J Pharm Pharm Sci 2012;4(3):291-5.

18. Akilen R, Pimlott Z, Tsiami A, Robinson N. Effect of short-term administration of cinnamon on blood pressure in patients with prediabetes and Type 2 diabetes. Nutrition 2013;29(10):1192-6.

19. Mustaffaa F, Hassan Z, Yusof NA, Razak KN, Asmawi MZ. Antidiabetic and antihyperlipidemic potential of standardized extract, fraction and subfraction of Cinnamomum iners leaves. Int J Pharm Pharm Sci 2014;6(5):220-5

20. Wainstein J, Stern N, Heller S, Boaz M. Dietary cinnamon supplementation and changes in systolic blood pressure in subjects with Type 2 diabetes. J Med Food 2011;14(12):1505-10.

21. Kalsi A, Singh S, Taneja N, Kukal S, Mani S. Current treatments for Type 2 diabetes, their side effects and possible complementary treatments. Int J Pharm Pharm Sci 2015;7(3):13-8. 